\title{
Design de calçados: uma aplicação para o desenvolvimento motor infantil.
}

Shoe design: an application for child motor skills development.

TRINDADE, Clara de Melo; Bacharel; Universidade do Estado de Minas Gerais

claramtrindade@gmail.com

BENATTI, Lia Paletta; Mestre; Universidade do Federal de Juiz de Fora

lia.paletta@gmail.com

\section{Resumo}

O presente relatório propõe como objetivo a concepção de um calçado que possa estimular o desenvolvimento motor refinado da criança e auxiliá-la na prática da atividade em foco, processo importante para o desenvolvimento, por envolver suas habilidades motoras, percepção visual, memorização sequencial, noção de espaço e tempo. A primeira etapa do protótipo passou por compreender o que compõe a atividade em estudo para pontuar em quais componentes do calçado seria possível a implementação de um facilitador para realização da tarefa, testando os componentes do tênis. Já a segunda etapa do projeto, consistiu na confecção de moldes para transformá-los em protótipos funcionais, tendo como validação final a pesquisa de campo com crianças para analisar se a proposta está de acordo com os objetivos do projeto. Por fim, a transformação do protótipo final em um tênis, originando o produto dentro dos processos produtivos existentes na cadeia calçadista.

Palavras Chave: design de calçados; desenvolvimento infantil; calçado infantil.

\begin{abstract}
The purpose of the current report is the development of a child footwear that aids children in the learning of how to tie shoes, because it involves their motor skills, visual insight, sequential memory and notion of time and space. The first step is to comprehend the sequential activity of tying a shoe and to punctuate what parts of the object are possible to interfere in, aiming to develop a tool that will ease the task. The second step consists in the production of castings to transform the shoes in functional prototypes, which will pass for several tests. As a final validation, the prototype was tested with kids to check if the proposition meets the project's objectives and finally, a pair of shoes is produced following the thorough footwear manufacturing process chain.
\end{abstract}

Keywords: shoe design; child development; child footwear. 


\section{Introdução}

O vigente projeto aborda sobre a concepção de um calçado infantil que tem como foco estimular o desenvolvimento motor refinado da criança na ação de amarrar o cadarço, aplicando os conceitos da Psicomotricidade e do Construtivismo, em que a criança é capaz de utilizar o seu próprio corpo como origem das aquisições cognitivas. Estima-se que a idade para o aprendizado dessa habilidade é a partir dos 5 anos, mas tal fator depende do meio em que a criança está inserida e do seu desenvolvimento motor e cognitivo. Os benefícios do conhecimento de uma tarefa que aparentemente parece simples, envolve o avanço cognitivo na criança, além da sua independência e liberdade em relação aos pais e aumento na sua autoestima por realizar uma tarefa sozinha.

$\mathrm{Na}$ fisiologia humana, existem dois tipos de habilidades motoras, as Habilidades Globais (HG) e as Habilidades Refinadas (HR) (MAGGIL, 2009). A primeira envolve o uso dos grandes músculos, ou seja, habilidades motoras fundamentais de menor precisão e maior impacto para realização de determinada atividade, como caminhar, correr, pular, dentre outros. Já as HR, que se enquadram no contexto do projeto, são grupos musculares que envolvem as extremidades dos corpos e que requerem maior controle dos pequenos músculos, principalmente aqueles utilizados na coordenação do movimento das mãos e dos dedos. Atividades relacionadas a esse tipo de exercício são a de escrever, digitar, apertar botões, amarrar o cadarço entre outros.

De acordo com a Associação Brasileira de Psicomotricidade (2016), "a psicomotricidade, é um termo empregado para uma concepção de movimento organizado e integrado, em função das experiências vividas pelo sujeito cuja ação é resultante de sua individualidade, sua linguagem e sua socialização", ou seja, a prática psicomotora deve ser entendida como um processo de ajuda que acompanha a criança em seu próprio percurso maturativo, que vai desde a expressividade motora e desenvolvimento até o acesso à capacidade de descentração (FONTANA, 2013).

Piaget (1977) enfatiza que as crianças são constantemente desafiadas por novos eventos e estímulos que, por sua vez, não são compreendidos de forma imediata. Assim, ele constrói e demonstra a ideia de que a inteligência é um modelo construtivista/interacionista, provocando que o desencontro entre o conhecimento existente e o meio inserido estimulam a atividade cognitiva da criança e o seu desenvolvimento intelectual. A partir da realização e análise do seu estudo clínico, o autor propôs que a inteligência é "uma forma de equilibração para a qual todas as estruturas cognitivas tendem" (PIAGET, 1977, p.6), em outras palavras, as atividades intelectuais acontecem com um intuito de produzir uma relação harmoniosa entre os pensamentos do indivíduo e seu meio.

A combinação das duas linhas de pensamento citadas anteriormente vislumbra os conceitos do projeto por procurar instigar a curiosidade da criança, ou seja, proporcionar que o aprendizado seja adquirido a partir dos próprios conhecimentos do usuário e de sua interação com o meio inserido.

\section{Objetivos}

O objetivo geral do projeto é a concepção de um tênis voltado ao público infantil com atributos que auxiliem o usuário na prática de amarrar o cadarço e desenvolva suas habilidades refinadas. Como objetivos específicos definem-se: 
- Utilizar o Construtivismo e a Psicomotricidade como estrutura de raciocínio do usuário, ou seja, fazer com que a criança participe ativamente do seu próprio aprendizado;

- Aplicar a memorização da ação em um tênis infantil, incluindo no objeto um sistema facilitador para repetição do exercício e auxílio na sua memorização;

- Atender o usuário final, pontuando que a criança seja capaz de aprender e repetir a ação dentro dos requisitos listados.

\section{Metodologia}

Após a delimitação do tema e do problema a ser abordado a primeira etapa do trabalho consistiu na elaboração do Briefing, tomando como base a estrutura apresentada por Philips (2007). O autor apresenta os elementos essenciais do Briefing, explicitando e sugerindo os principais tópicos para o desenvolvimento do projeto. Neste projeto as informações utilizadas se apresentam na tabela 1.

Tabela 1 - Principais conteúdos dos tópicos básicos do Briefing de design.

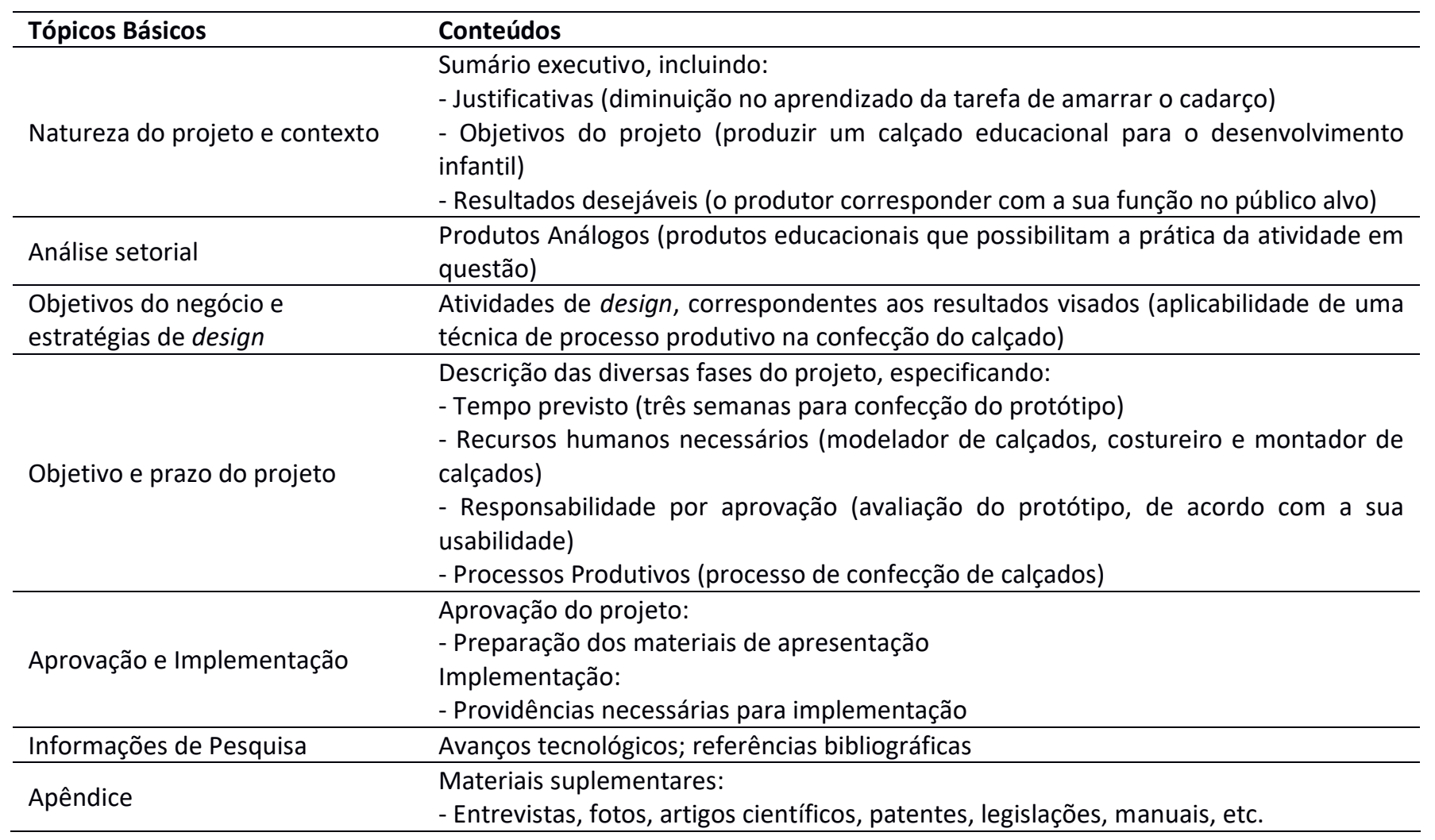

Fonte: Phillips, 2007 (Modificado pelo autor).

\section{Desenvolvimento}

O desenvolvimento projetual seguiu a seguinte sequência organizacional: definição de público alvo, análise setorial, geração de alternativas, testes e resultados. 
Assim para a etapa de público-alvo foi definido crianças a partir dos 5 anos de idade, que se encontram no grupo de Estágio Pré-Operacional definidos por Piaget (1977), que usa o pensamento intuitivo, racionando a partir de intuições. Esse público atende tanto o sexo feminino quanto masculino, sendo difusores de tendência, principalmente por já ter independência perante os pais nas escolhas das peças a serem vestidas e por se idealizarem nos seus personagens favoritos de desenhos animados ao se vestirem.

O levantamento de produtos que auxiliam a aprendizagem da ação de amarrar o cadarço realizado como etapa de análise setorial, em sua maioria, encontram-se projetos separados do calçado para a criança realizar a tarefa, situados em livros como o "Zoo's Shoe" (Fig. 2a), bonecos interativos como o Cebolinha da Turma da Mônica que oferecem diferentes tarefas a serem realizadas em seu escopo (Fig. 1b), placas facilitadoras da ação como a "EzLeapz" e "Loopez" (Fig. 2c e 2d) e também produtos Do it Yourself (DIY), isto é, "faça você mesmo". (Fig. 2e).

Figura 2 - Produtos análogos
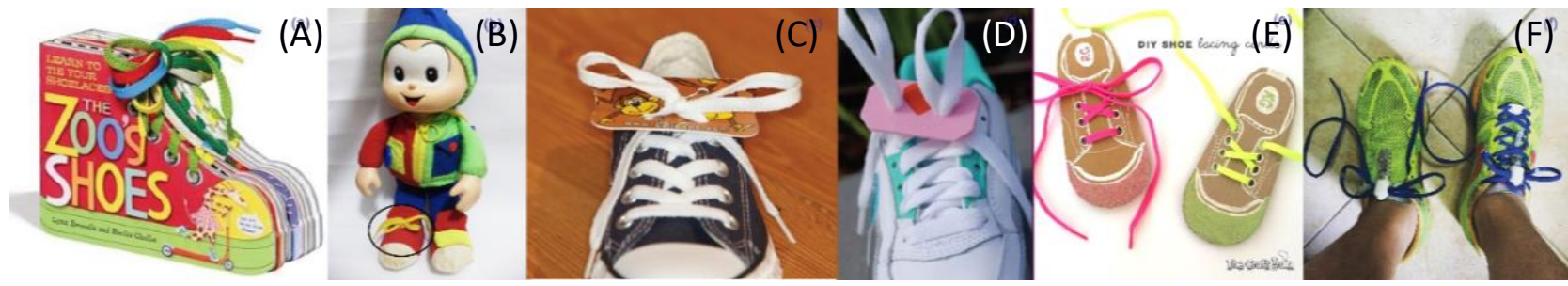

Fonte: domínio público (2016)

Dentro da pesquisa, também se encontrou produtos que anulam a ação a ser realizada pela criança, o cadarço sempre estará amarrado (Fig. 2f) pois o seu laço encontrasse em um nó situado no final da lingueta.

Figura 3 - Mapa mental.

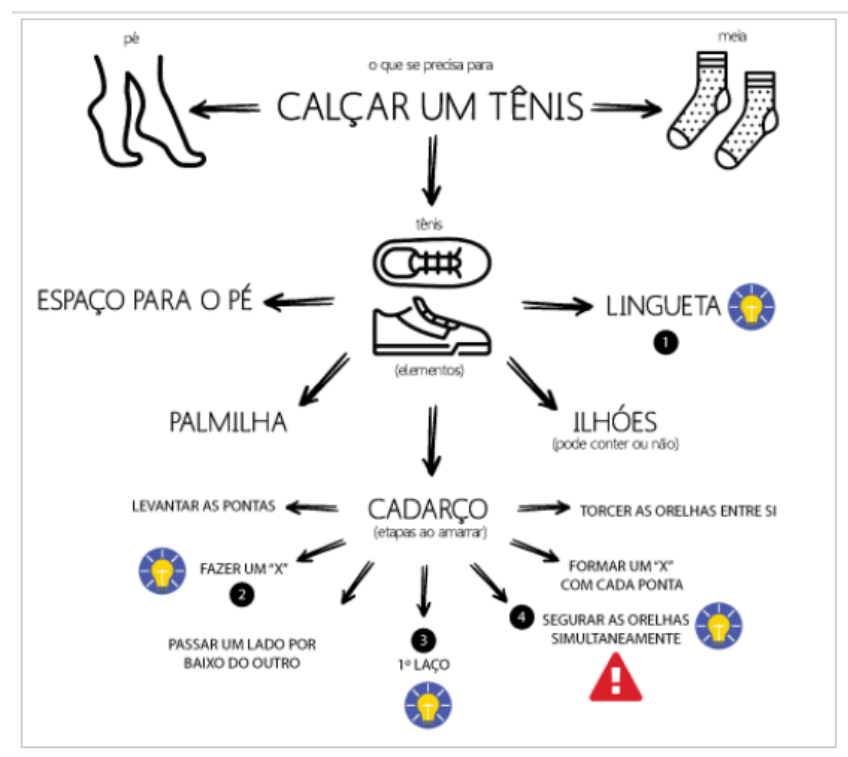

Fonte: elaborado pelo autor (2016) 
Para desenvolvimento de proposta de calçado, inicialmente idealizou-se um mapa mental da situação-problema para vislumbrar alternativas possíveis de projeto (Fig. 3), dentro das possibilidades de usar a lingueta como suporte, marcação com costura no cadarço e utilização de um suporte para segurar as orelhas simultaneamente. A partir disso, utilizou-se uma forma para melhor percepção de tamanho, manuseio e tentativas da alternativa mais adequada para repetição do movimento refinado de amarrar o cadarço. Após a obtenção da forma (Fig. 4a), foi possível obter uma representação tridimensional a partir do Scanner 3d Artec Leo da peça (Fig. 4b), que gerou sua digitalização. Assim, com um arquivo em formato STL foi feita a prototipagem rápida.

Figura 4 - Etapas de prototipagem da forma de calçado.

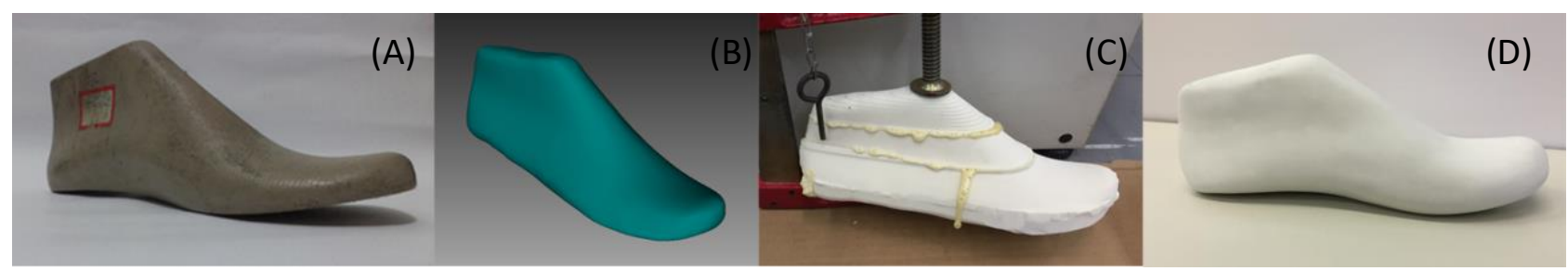

Fonte: elaborado pelo autor (2016).

Após a conclusão da digitalização, o arquivo para prototipagem foi levado e dentro das opções inseridas no laboratório, foi escolhida a Fresadora Rolland MDX-40A, máquina destinada para usinagem e o material selecionado foi o Poliuretano com densidade de $600 \mathrm{~kg} / \mathrm{m}^{3}$. Assim que o objeto foi retirado da fresadora (Fig. 4c), deu-se acabamento na peça com massa plástica e uma finalização com lixa d'água (Fig. 4d).

Figura 5 - Moldes de papietagem e protótipo definido.
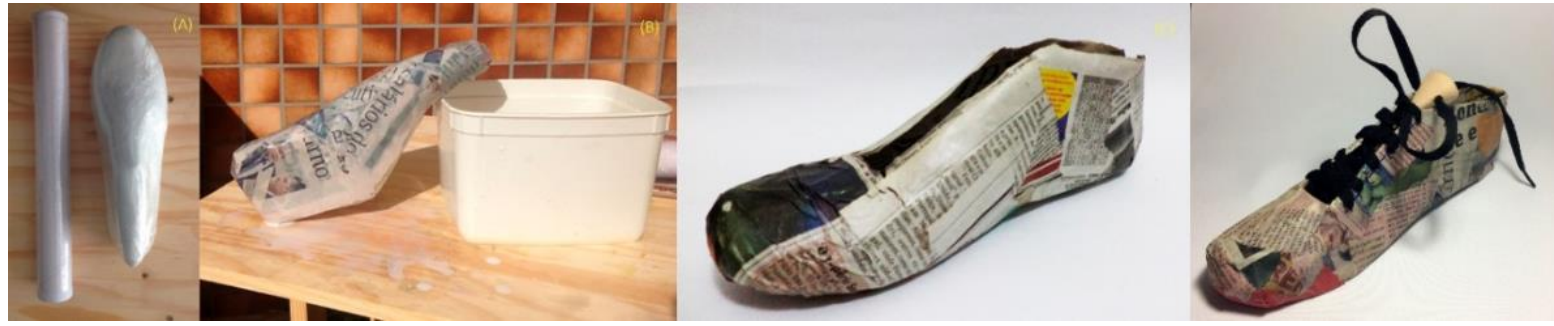

Fonte: elaborado pelo autor (2016)

A técnica de papietagem entra como alternativa de modelagem por permitir moldar e replicar diferentes formatos de objetos com precisão, dependendo da forma inicial a ser utilizada (Fig. 5). As alternativas inseridas na lingueta do calçado (Fig. 6), realizada em um modelo físico, apresentou melhores soluções para a situação-problema. Principalmente por permitir que a inserção de diferentes possibilidades e formas de manuseio fossem mais adequadas ao uso. A opção selecionada para aplicação no projeto foi a de uma furação no corpo da lingueta, permitindo que o cadarço fique firme e formado para que as crianças possam finalizar o laço. Devido aos processos produtivos existentes na indústria calçadista, a opção selecionada atende os requisitos propostos, tendo em vista que as outras opções causariam irregularidade na parte 
superior do corpo da lingueta ou por não existir um ilhós que possua um rasgo no seu corpo para ocasionar em uma facilitação de retirada do cadarço do local inserido.

Figura 6 - Geração de alternativas na lingueta (marcas de corte).
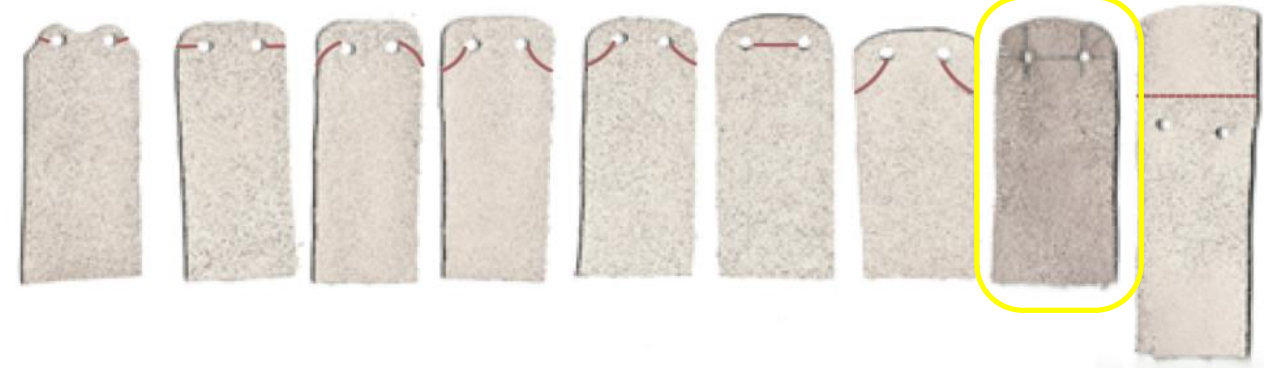

Fonte: elaborado pelo autor (2016)

A fim de confirmar a decisão tomada perante a geração de alternativas durante o desenvolvimento do projeto, foi possível a realização de um teste com crianças da faixa etária estabelecida e uma entrevista com a professora responsável.

A proposta escolhida é apresentada em esquema gráfico na figura, em que os dois furos na lingueta do calçado auxiliam a amarração. Assim no momento do laço, em que normalmente as duas mãos executam simultaneamente a tarefa de amarrar o calçado, a criança pode utilizar os furos para posicionar o cadarço e assim dedicar maior atenção e tempo além tentar diferentes manejos, sem perder a trajetória até ali alcançada e ainda assim, definir por si a melhor forma de executar a função.

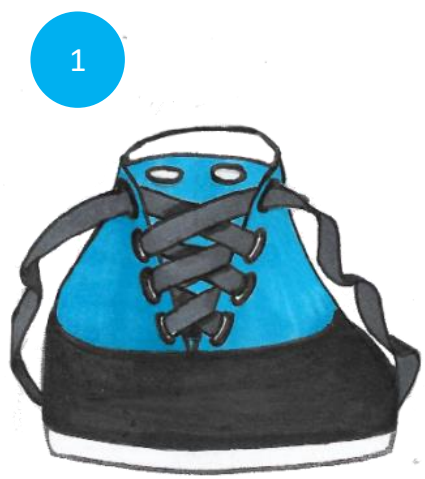

Figura 7 - llustração de usabilidade.
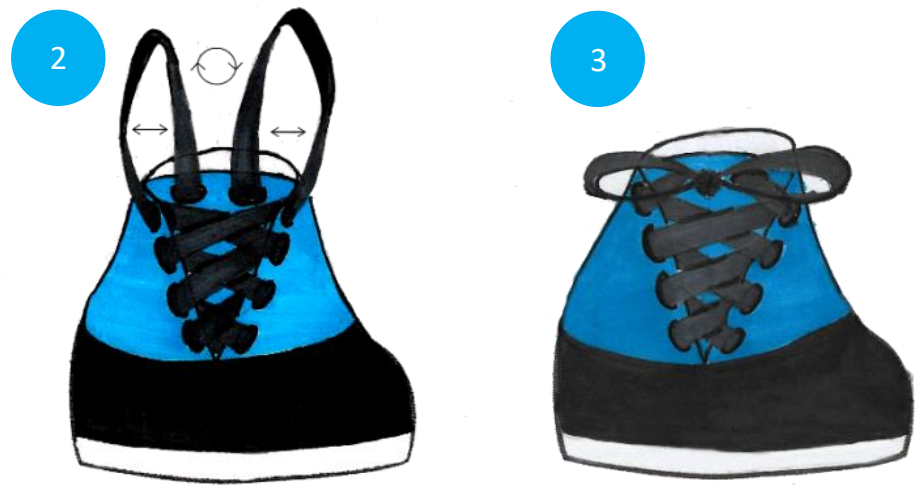

Fonte: elaborado pelo autor (2018).

O Centro Educacional Tia Marida Marida - CETIM é uma escola situada na cidade de Belo Horizonte que atende crianças desde o berçário até a pré-escola, com foco no desenvolvimento pessoal e intelectual. A escola disponibilizou seu espaço e alunos para validação da proposta.

O teste com o protótipo funcional foi realizado com 5 alunos, sendo 3 deles com 5 anos e 2 com 6 anos. A proposta estabelecida era reproduzir para as crianças a antiga metodologia de 
amarrar o cadarço e em seguida, pedi-los para repetir a tarefa. Depois apresentar a nova proposta e pedir novamente para as crianças reproduzir a ação. Os resultados se apresentam na tabela 2 .

Tabela 2 - Teste do protótipo em crianças entre 5 e 6 anos.

\begin{tabular}{|c|c|c|c|c|}
\hline Criança & Idade (anos) & Já sabe amarrar o cadarço? & Apresentou dificuldade? & Outros \\
\hline 1 & 5 & Não & - & $\begin{array}{l}\text { A criança não quis realizar o } \\
\text { teste. }\end{array}$ \\
\hline 2 & 6 & Sim & Não & $\begin{array}{l}\text { A criança afirmou que a nova } \\
\text { proposta auxiliaria os colegas de } \\
\text { outra escola que não sabem } \\
\text { amarrar o cadarço, } \\
\text { aprenderem. }\end{array}$ \\
\hline 3 & 5 & Não & Sim & $\begin{array}{l}\text { A criança afirmou que a nova } \\
\text { proposta era mais difícil, mas ao } \\
\text { repetir a ação, realizou a tarefa } \\
\text { proposta sem nenhuma } \\
\text { dificuldade. }\end{array}$ \\
\hline 4 & 5 & Não & Não & - \\
\hline 5 & 6 & Sim & Sim & $\begin{array}{l}\text { A criança afirmou ser mais difícil } \\
\text { por já saber amarrar o cadarço. }\end{array}$ \\
\hline
\end{tabular}

Fonte: elaborado pelo autor (2016)

As duas crianças de 6 anos afirmaram já saber amarrar o cadarço, mas uma delas apresentou dificuldade em reproduzir a nova proposta, e afirmou que considera a mesma mais difícil por já saber amarrar o cadarço da forma convencional. Já a outra criança, conseguiu realizar a nova proposta sem nenhuma dificuldade e afirmou que esse mecanismo auxiliaria seus colegas de sala que não sabem realizar a tarefa a aprenderem. Já as crianças de 5 anos, todas não sabiam amarrar o cadarço, mas uma não quis realizar o teste. Já as outras duas, realizaram sem nenhum problema e mesmo uma delas afirmar que achou a nova proposta mais difícil, ao pedir para repetir a ação, ela reproduziu a tarefa proposta sem nenhuma dificuldade. Conclui-se que o teste foi satisfatório e que a proposta estabelecida é factível com os objetivos do projeto, possibilitando o aprendizado da criança em amarrar o cadarço com um facilitador em seu calçado.

Por fim, a professora responsável passou por uma entrevista, e afirmou que a atividade é praticada na escola, mas em objetos $2 \mathrm{D}$ e considerou a abordagem de apresentar a tarefa em um modelo 3D mais efetiva para o aprendizado. Além disso, apesar de ter atividades em sala que fazem com que as crianças pratiquem as $\mathrm{HR}$, a escolha dos calçados que as crianças utilizam para ir à escola dificulta o aprendizado da tarefa de amarrar o cadarço, pois a maioria dos alunos vão com sandálias abertas ou tênis de velcro. Em vista de todas essas informações, a professora também sugeriu que um acompanhamento fosse realizado com as crianças que fossem adquirir o calçado, para concluir se elas são capazes de superar a dificuldade apresentada sem depender da proposta estabelecida. 
Figura 8 - Etapas de confecção do calçado

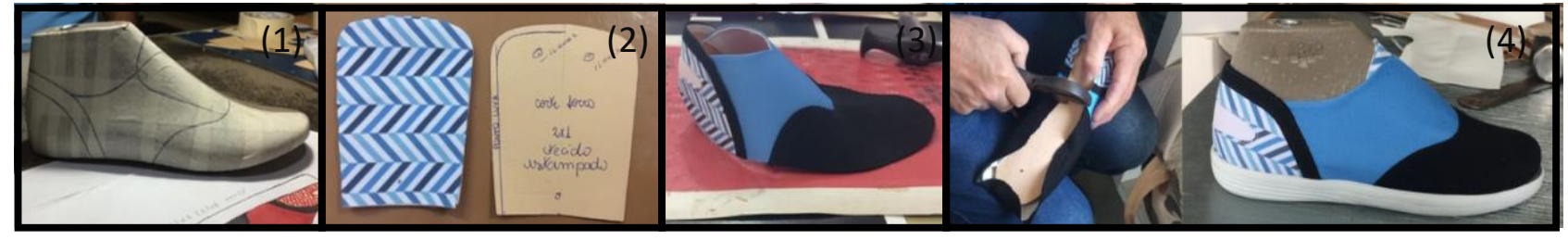

Fonte: elaborado pelo autor (2016)

Para o desenvolvimento do protótipo (figura 8), por se tratar de um modelo de tênis, o objeto exigiu que no seu processo ocorresse a junção do cabedal, parte superior do sapato destinada a proteger e cobrir a parte de cima do pé; e solado, que é o conjunto de peças que formam a parte inferior do sapato e que se interpõem entre o pé e o solo. Essa junção se dividiu entre as seguintes etapas (CHOKLAT,2012; LIGER, 2015):

1. Modelagem: desenvolvimento do molde a partir do desenho do calçado, identificação e adaptação do modelo projetado, definição da forma, materiais e componentes para a construção do protótipo;

2. Corte: segmentação da matéria prima que comporá o cabedal (cabedal, forro, couraça, contraforte e suador). Demanda precisão do operador quando o processo é conduzido de forma manual a partir dos moldes adquiridos da etapa anterior;

3. Costura: A partir dos componentes cortados, as partes da modelagem são costuradas entre si, com o uso de máquinas de coluna, para a formação do cabedal;

4. Montagem e acabamento: união do cabedal com o solado na forma do sapato. A finalização se inicia com a fixação da sola de montagem na forma, para melhor aderência e conformação do cabedal na sola, fixada manualmente. Passa-se cola para conformação do cabedal na sola de montagem e, por fim, esta é colada no conjunto e pressionada para maior adesão.

O protótipo em estudo passou por todas as etapas citadas anteriormente, realizadas por terceiros com expertise no processo. A conjuntura e uso e final do calçado pode ser vislumbrada na Figura 9.

Figura 9 - Protótipo confeccionado.

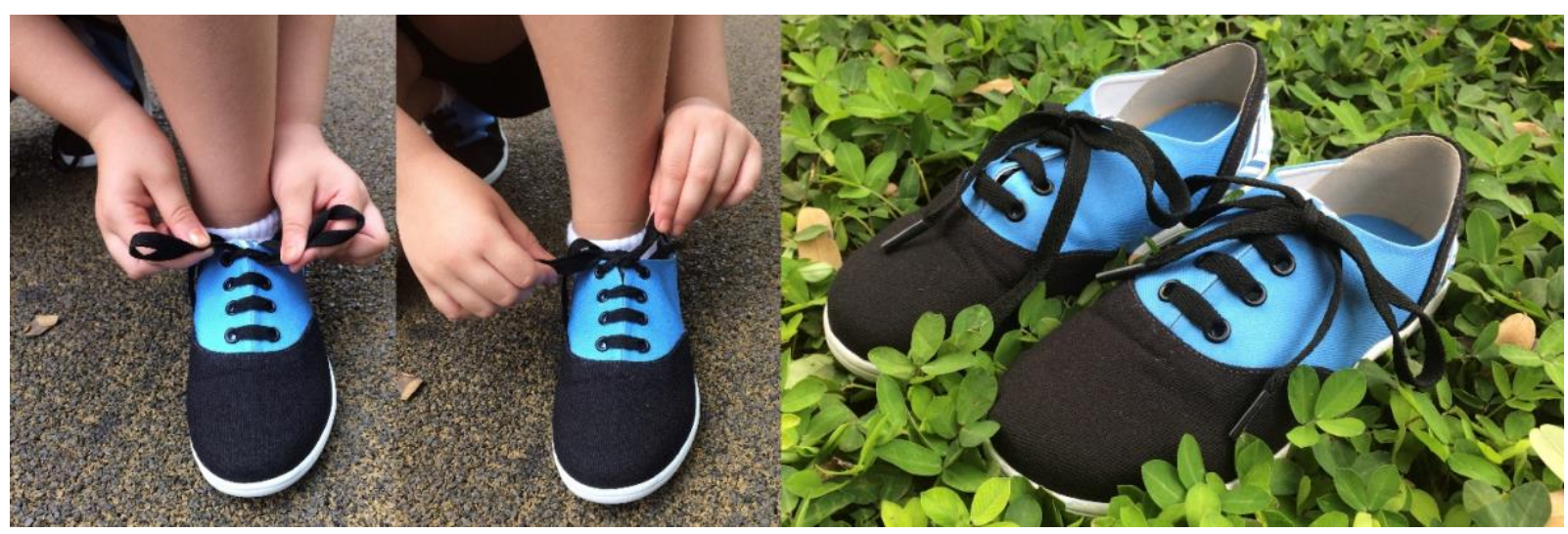

Fonte: elaborado pelo autor (2016) 


\section{Considerações finais}

O projeto propõe o desenvolvimento de um calçado infantil voltado para a aprendizagem da técnica de amarrar cadarço, considerando as qualidades inseridas para o desenvolvimento da criança. Notou-se a preocupação do mercado em proporcionar produtos que possibilitam a prática da atividade, mas nenhuma inserida no próprio calçado, sendo isso um diferencial do projeto no mercado. Além disso, o facilitador da tarefa foi aplicado com êxito, devido ao resultado obtido a partir dos testes realizados com o protótipo funcional.

Esse projeto possibilita pesquisas futuras dentro da temática, como no acompanhamento das crianças que usufruírem do produto ao longo de um período, e também promove o desenvolvimento de um mecanismo que seja aplicado em diferentes modelos de calçados e até mesmo possibilidades de novas intervenções no processo fabril calçadista.

\section{Agradecimentos}

Agradecemos ao Centro Design Empresa (CDE) e ao Centro de Estudos em Design da Madeira (CEMA) pelo suporte técnico com os equipamentos de prototipagem. A escola CETIM pela disponibilização para realização dos testes com o protótipo em seu espaço e ao modelista José Reni e sapateiro Paolo pela parceria para o desenvolvimento do calçado.

\section{Referências}

ASSOCIAÇÃO BRASILEIRA DE PSICOMOTRICIDADE. O que é Psicomotricidade. Disponível na internet em http em: < http://psicomotricidade.com.br/sobre/o-que-e-psicomotricidade/>. Acesso em 15 de abr. 2016.

CHOKLAT, Aki. Design de sapatos. São Paulo: Editora Senac, 2012.

FONTANA, Cleide Madalena. A importância da psicomotricidade na educação infantil. 2012. 78 p. Monografia (Especialização em Educação: Métodos e Técnicas de Ensino). Universidade Tecnológica Federal do Paraná, Medianeira, 2012.

LIGER, Ilce. Modelagem de calçados: técnicas e passo a passo. São Paulo: Editora Senac São Paulo, 2015.

MAGILL, Richard A. Motor learning and control: concepts and applications. McGraw-Hill Education, 2009.

PIAGET, Jean. O desenvolvimento do pensamento: equilibração das estruturas cognitivas. Lisboa: Dom Quixote, 1977.

PHILLIPS, Peter. Briefing: a gestão do projeto de produto. São Paulo: Blucher, 2007. 